\title{
AMAZÔNIA CONSILIENTE E AMAZÔNIA DAS ECOLOGIAS DE SABERES: DIÁLOGOS PARA A CONSERVAÇÃO DA NATUREZA EM ÁREAS PROTEGIDAS
}

\section{CONSILIENT AMAZON AND AMAZON OF THE ECOLOGIES OF KNOWLEDGE: DIALOGUES FOR THE CONSERVATION OF NATURE IN PROTECTED AREAS}

Marco Antonio Chagas 1
https://orcid.org/0000-0002-4792-9154
http://lattes.cnpq.br/8349011053672474

Janaina Freitas Calado ${ }^{2}$

http://orcid.org/0000-0002-7489-0080 http://lattes.cnpq.br/1338785057520974

\section{Antônio Sérgio Monteiro Filocreão ${ }^{3}$}

http://orcid.org/0000-0002-8259-8805

http://lattes.cnpq.br/8321993369800090

Recebido em: 2 de Abril de 2020.

Aprovado em: 20 de julho de 2020

RESUMO: A conservação da natureza na Amazônia acolhe uma multiplicidade de perspectivas e pontos de vista que transitam no interregno natureza e cultura. Este artigo analisa conhecimentos nos campos das ciências naturais e das ciências sociais, com aporte de categorias ainda pouco visibilizadas pela ecologia política que se faz presente em processo de lutas pela conservação da natureza em áreas protegidas na Amazônia. Filia-se à afirmação das Epistemologias do Sul para ressignificar conceitos e evidenciar subjetividades e territorialidades para ação coletiva de resistência ao capitalismo das commodities impulsionado pelo EstadoMercado. Aponta caminhos para complementaridades epistemológicas entre conhecimentos e saberes ecológicos identificados em práticas nas terras indígenas, reservas extrativistas e outras áreas protegidas na Amazônia.

Palavras-chave: Amazônia. Epistemologias do Sul. Ecologia de Saberes. Áreas Protegidas.

\footnotetext{
${ }^{1}$ Doutor em Desenvolvimento Socioambiental pelo Núcleo de Altos Estudos Amazônicos da Universidade Federal do Pará (NAEA/UFPA). Professor do Departamento de Meio Ambiente e Desenvolvimento e do Programa de PósGraduação em Desenvolvimento Regional da Universidade Federal do Amapá (UNIFAP). E-mail: marco.chagas@uol. com.br.

${ }^{2}$ Doutora em Ecologia pela Universidade Federal do Rio Grande do Norte (UFRN). Professora do Curso de Licenciatura em Ciências Naturais da Universidade do Estado do Amapá (UEAP). E-mail: janaina.calado@ueap.edu.br.

${ }^{3}$ Doutor em Desenvolvimento Socioambiental pelo Núcleo de Altos Estudos Amazônicos da Universidade Federal do Pará (NAEA/UFPA). Professor do Departamento de Filosofia e Ciências Humanas e do Programa de Pós-Graduação em Desenvolvimento Regional da Universidade Federal do Amapá (UNIFAP). E-mail: afilocreao@gmail.com.
} 
ABSTRACT: The conservation of nature in the Amazon embraces multiple perspectives and points of view, which are placed in the nature and culture interregnum. This paper analyses knowledge in the fields of natural and social sciences, bringing concepts still poorly visible by the political ecology that is present in struggles for the conservation of diversity in Amazonian protected areas. The article commits to the affirmation of the epistemologies of the South to give new meaning to concepts and to shed light upon subjectivities and territorialities for the collective action of resistance against commodity-driven capitalism, the one boosted by the State-Market. The paper also points paths towards an epistemological complementation among ecological knowledge concretely identified in indigenous lands, extractive reserves and other protected areas in Amazon.

Keywords: Amazon. Epistemologies of the South. Ecology of Knowledge. Protected Areas.

\section{INTRODUÇÃO}

Este texto coloca a Amazônia no foco da negação do óbvio ao propor discutir um tema aparentemente de consenso no imaginário de todos aqueles que defendem a maior floresta tropical do planeta: a conservação da natureza. Não se trata de um "sim" à pergunta de Bensusan (2008): “seria melhor mandar ladrilhar?”. Mas, uma inquietação diante de conceitos que seguem o cânone hegemônico das ciências naturais de fundamentação globalocênrica e de ecologia política ainda distante de uma práxis descolonizadora.

Não menos óbvio também é o fato da Amazônia ser sempre pensada como um lugar atrasado, a ser civilizado pelo desenvolvimentismo, como muitos propagam em continência aos sucessivos planos de governos para a região. Mas o que isso significa? O antropólogo Eduardo Viveiros de Castro responde: “o Estado se aliou ao mercado, contra a natureza e contra a cultura” (CASTRO, 2012). E com isso, a natureza e os conceitos que a cercam foram abduzidos pela ignorância da única alternativa traduzida em recursos a serem explorados.

O agressivo avanço do capitalismo das commodities sobre a Amazônia é apenas a continuidade de processos políticos que seguem a lógica hierárquica do colonialismo histórico, denominado por Quijano (2005) de colonialidade, que não reconhece a diversidade biocultural ${ }^{4}$ dos povos originários e tradicionais, seus saberes e fazeres ecológicos artesanais, portanto, são subjugados pela doutrinação tóxica dos fatos esquecidos e dos interesses mais imediatistas das verdades incertas.

A fagocitose do capitalismo ${ }^{5}$, categoria filiada à "falha metabólica" de Marx (FOSTER, 2005), contribui para a compreensão da disputa pela apropriação do aparato estatal pelas vias da democracia representativa, mas também pelas vias da cooptação e da violência, quando então se mostra como um sistema oportunista marcado por profundas cicatrizes nos territórios explorados (QUIJANO, 2005; MENESES, 2015; 2018).

Esse modelo capitalista e colonialista de exploração que levou ao genocídio de várias tri-

\footnotetext{
${ }^{4}$ As maiores reservas de biodiversidade que restam nas américas estão nos territórios indígenas, formando a denominada diversidade biocultural (ALIMONDA, 2011, p. 48).

5 "Fagocitose do capitalismo": metáfora utilizada pelos autores para se referir à capacidade do capitalismo de englobar e destruir resistências como forma de impor seu poder e dominação.
} 
bos indígenas e que apagou parte da cultura da floresta é descrito com propriedade por Souza (2019), que vai mais além ao desmitificar o mito do vazio amazônico e de terra habitada por povos primitivos:

Os últimos avanços da arqueologia na Amazônia vêm corroborar a tese de que a cultura da selva tropical foi capaz não apenas de formar sociedades perfeitamente integradas às condições ambientais como também de estabelecer sociedades complexas e politicamente surpreendentes (SOUZA, 2019, p. 48).

E a violência colonial continuou... A partir do século XVIII a Amazônia passou por diferentes fases de uma modernidade (neo)colonialista e culturalmente racista. Primeiro com as propriedades agrárias escravocratas indígenas e posteriormente negras, adentrando os séculos XIX e XX com o ciclo da borracha, as tentativas de domesticação da floresta (Fordlândia - Jari) ${ }^{6}$ e a mineração do trem sem volta (Serra do Navio/Amapá e Carajás/Pará).

O discurso da modernização da Amazônia é sempre revisitado por sucessivos governos, desde a ditadura militar (Plano de Desenvolvimento Econômico da Amazônia - 1966), até a democracia de baixa intensidade (Brasil em Ação - 1996; Avança Brasil - 2000, Programa de Aceleração do Crescimento/Plano Amazônia Sustentável - 2008).

Do genocídio indígena ao epistemicídio ${ }^{7}$ de saberes, perceber a recorrência dessas alienações desenvolvimentistas requer descolonizar as mentes em defesa da autoconscientização, para então ressignificar os territórios e se permitir um reencontro com os princípios que regem a ecologia dos povos adaptados à cultura da natureza e da floresta (ROMÃO; GADOT'TI, 2012; SANTOS, 2019).

As fronteiras discursivas entre ciência e ecologia de saberes apresentam campos de sobreposição que favorecem ações voltadas para a conservação da natureza e de territórios que se pretende manter protegidos. Silva (2015, p. 253) fortalece essa complementaridade ao destacar que: "a cooperação entre os saberes tradicionais e o conhecimento científico pode comunicar caminhos alternativos a uma conservação da biodiversidade afinada com valores para além dos interesses de mercado".

A fundamentação epistêmica deste artigo é percorrida pela confrontação de conhecimentos ou disputas cognitivas em relação à conservação da natureza, deixando bem claro que não significa hierarquizar as ciências nem os conhecimentos associados. Para impulsionar o pensamento crítico sobre a conservação da natureza se dialogou com autores das ciências naturais e das ciências sociais, com ênfase na produção científica de origem naturalista de Edward Wilson e com os aportes teóricos de Arturo Escobar e Boaventura de Sousa Santos ancorados nas epistemologias do Sul.

A opção pela literatura de Edward Wilson deve-se à sua referência mundial sobre o tema natureza/biodiversidade e proposições de explicações científicas a partir de diferentes disciplinas que denomina "consilientes", de indução ecológica profunda (ética da natureza) e

\footnotetext{
${ }^{6}$ No museu da empresa Jari, localizado em Monte Dourado, Pará, um quadro com citação de Daniel Ludwig, empresário norte-americano que em 1967 recebeu do governo militar 3,5 milhões de hectares para implantar o Projeto Jari, chama atenção pelo enunciado: "meu sonho é ver a floresta crescer como um grande milharal".

${ }^{7}$ Epistemicídio: termo usado por Santos (2019, p. 27) para chamar atenção para "à destruição de uma imensa variedade de saberes que prevalecem sobretudo do outro lado da linha abissal - nas sociedades e sociabilidades coloniais. Tal destruição desarmou essas sociedades, tornando-as incapazes de representar o mundo como susceptível de ser mudado por via do seu próprio poder e no sentido de prosseguir os seus próprios objetivos”.
} 
acervo dos mais instigantes em relação as áreas protegidas (WILSON, 1988; 1997; 1999; 2008; 2012; 2013; 2018; 2019).

Por sua vez, Arturo Escobar e Boaventura de Sousa Santos afinam-se pela busca de novos saberes para o conceito de natureza, tornando-o plural e percebido diante de um contexto crítico de relações de interesse capitalista e colonialista com argumentos associados ao reposicionamento epistemológico a partir das experiências do Sul ${ }^{8}$ (ESCOBAR, 1998; 2007; 2011; 2015; SANTOS, 2002; 2005; 2006; 2019).

Para contextualizar a prática das ciências em debate, optou-se pelo caso da conservação da natureza do estado do Amapá, na Amazônia brasileira. A referida escolha deve-se a geografia política e ambiental singular desse território, a diversidade de representações de espaços destinados à salvaguarda da natureza e a presença de populações indígenas, quilombolas, ribeirinhos, castanheiros, entre outros grupos sócias que têm seus sustentos e modos de vida relacionados à ecologia da floresta, mas que também estão em constantes ameaças pelo consenso das commodities (SVAMPA, 2012).

O texto não trata de uma discussão conceitual sobre natureza e cultura, nem da diversidade de regimes e categorias que as delimitam ou as enquadram, como frequentemente acontece quando se fala de meio ambiente na tradição ocidental, com inequívocos mal-entendidos relacionados à tradução intercultural de "línguas que não sabemos que sabíamos" (COUTO, 2016). Refere-se, tão somente, a um diálogo desprovido de intenção de subalternidade entre as ciências, no sentido de trazer a conservação da natureza em áreas protegidas para o campo da ecologia política e com isso evidenciar subjetividades e territorialidades para ação coletiva de resistência.

Existe uma grande variedade de campos disciplinares na área ambiental que buscam estabelecer pontes entre as ciências naturais e sociais, com importantes contribuições para a ampliação de teorias, metodologias e práticas (p. ex. política ambiental, sociologia ambiental, história ambiental, economia ambiental, educação ambiental, ecologia e etc.). Entretanto, a maioria desses campos, na busca pelas descobertas ou controle da natureza, acaba por secundarizar a diversidade cultural ou apenas usá-la como um trampolim para suas pesquisas (PRETTY et al., 2009; SILVA, 2015; BERKES, 2017; DIEGUES, 2019). 9

Por despertar sentidos e sentimentos múltiplos em torno da conservação da natureza, optou-se por abordar o caso do Amapá, estado localizado mais ao Norte da Amazônia brasileira, que destina $73,7 \%$ de seu território de cerca de $145.000 \mathrm{~km}^{2}$ para a conservação da natureza em áreas protegidas e que alimenta simbolicamente o discurso de "o estado mais preservado do Brasil”. O Amapá também se tornou conhecido por abrigar por quase 50 anos o primeiro e controverso megaprojeto capitalista de exploração mineral na Amazônia, ${ }^{10}$ que de certa forma antecipou o antagonismo "natureza/recurso natural" que tem dominado o debate ambiental e desenvolvimentista no mundo, sobretudo na América Latina.

A princípio, parte-se da hipótese de que as áreas protegidas criadas na Amazônia fazem

\footnotetext{
8 Trata-se de um Sul não geográfico, mas metafórico enquanto representação de conhecimentos e saberes nascidos em lutas contra o capitalismo, o colonialismo e o patriarcado (SANTOS, 2019).

9 Pretty et al. (2009) e Berkes (2017) são autores que fazem parte da escola conservacionista norte-americana, com filiação ao campo da filosofia da ética da natureza de Henry Thoreau, John Muir, Aldo Leopoldo e outros adeptos ao modelo "Yellowstone Park".

10 Entre 1953 a 1998, as jazidas de manganês localizadas em Serra do Navio, no Amapá, uma das maiores e melhores do mundo, foram exploradas até a exaustão por uma empresa nacional (ICOMI) financiada e controlada por capital norteamericano.
}

PRACS: Revista Eletrônica de Humanidades do Curso de Ciências Sociais da UNIFAP https://periodicos.unifap.br/index.php/pracs ISSN 1984-4352 Macapá, v. 13, n. 2, p. 341-360, jul./dez. 2020 
parte da consolidação de uma política territorial globalocêntrica voltada para a conservação da natureza, com conexões frágeis à políticas alternativas que envolvam a dimensão humana das ecologias de saberes e essas ausências ou distanciamentos têm dificultado a organização de lutas e de resistência ao capitalismo predatório, bem como a construção de alternativas. Entretanto, artesanias das práticas ${ }^{11}$ em áreas protegidas na Amazônia sinalizam aprendizados não alinhados que dialogam com as epistemologias do Sul. ${ }^{12}$

Argumenta-se ainda que os territórios amazônicos sejam pensados e articulados coletivamente para além das linhas traçadas pelo Estado, ampliando o conceito de conservação da natureza em áreas protegidas, com reposicionamento estratégico conciliatório entre as ciências (naturais e sociais) e protagonismo a partir das ecologias de saberes dos povos da floresta.

\section{ENFOQUES EPISTEMOLÓGICOS SOBRE NATUREZA}

O desmatamento da floresta amazônica está na gênese do conceito de natureza associado a biodiversidade. Este termo foi cunhado pelo biólogo norte-americano Thomas Lovejoy nos idos dos anos 1980, quando de suas pesquisas sobre a fragmentação da floresta amazônica. Entretanto, a literatura atribuiu ao naturalista Edward Wilson a popularização do termo em função do uso "Biodiversity" no relatório do Fórum Norte-Americano sobre Biodiversidade, publicado em formato de livro em 1988, nos EUA e em 1997 no Brasil (WILSON, 1988; 1997; BENSUSAN, 2008; FRANCO, 2013).

O Fórum realizado em 1986 na capital norte-americana, Washington, reuniu cientistas naturais para analisar o ritmo da destruição das florestas tropicais e a consequente extinção da biodiversidade, com autoafirmação do paradigma dominante e ataques aos cientistas sociais:

Os políticos e cientistas sociais que questionam a extensão das atuais extinções estão apenas demonstrando sua profunda ignorância em ecologia; a modificação do hábitat e sua destruição e a extinção de populações e espécies andam de mãos dadas (EHRLICH, 1997, p. 29).

Se comunidades científicas rivalizam conhecimentos, vem de Edward Wilson a proposta conciliatória. O cientista natural propôs "biologizar o social" como uma expressão de racionalidade para a conservação da natureza:

[...] segue-se que as ciências biológicas são essenciais para se alcançar a coerência entre todos os ramos do saber, das humanidades até descer às ciências físicas. A tarefa é um tanto facilitada pelo fato de que as disciplinas dentro da própria biologia tornam-se cada vez mais consilientes a cada ano (WILSON, 1999, p. 77).

A proposta da "consiliência", feita por Wilson, trata-se de uma manifestação metódica do conhecimento que busca aproximar as ciências naturais das ciências sociais, estas por sua vez

\footnotetext{
11 Artesanias das práticas, termo usado por Santos (2019, p. 61), refere-se ao trabalho artesanal de comunidades que não se enquadra em modelos, portanto, mantém-se não alinhado a qualquer processo de universalidade, sem perder de vista que isso representa a luta pela preservação de suas culturas e da própria sobrevivência.

12 “As epistemologias do Sul referem-se à produção e validação de conhecimentos ancorados nas experiências de resistência de todos os grupos sociais que têm sido sistematicamente vítimas da injustiça, opressão e destruição causadas pelo capitalismo, pelo colonialismo e pelo patriarcado" (SANTOS, 2019, p. 17).
} 
subestimadas como "ametódicas e ateóricas". O conceito representa uma espécie de unidade fundamental de todo conhecimento. Segundo o naturalista, consiliência trata-se de um salto conjunto do conhecimento que permite a ligação de fatos com a teoria, baseado em todas as disciplinas, para criar uma explicação cientificamente aceita.

A única forma de estabelecer ou refutar a consiliência é por meio da análise racional das ciências naturais, pois as ciências sociais não são capazes de construir metodologias de pesquisa e de formular teorias verdadeiramente científicas (WILSON, 1999, p.7; 2013, p. 357).

A pesquisa científica sobre conservação da natureza tem abrangido predominantemente temas de interesses das ciências naturais e pautado as agendas institucionais, principalmente quanto à imposição de uma condição de "Estado Laboratorial" que invariavelmente segue as seguintes prioridades: i) quantificação da natureza; ii) causas e consequências de sua destruição; iii) funcionamento dos ecossistemas; iv) verificação da relação entre natureza e os serviços providos pelos ecossistemas, entre outros temas afins (SANTOS, 2005, p. 138-140; SANTOS, 2006, p. 154).

Os conceitos associados à natureza evoluíram com os cientistas naturais e firmaram-se enquanto comunidades que compartilham estratégias voltadas para a conservação da natureza intocada. O paradigma hegemônico de natureza refuta possibilidades de novos objetos de pesquisas que estejam fora das definições consagradas pelo campo das ciências naturais, com críticas às humanidades por se distanciarem das ciências (WILSON, 1999; 2018).

O modelo de conservação da natureza praticado nos trópicos é uma construção derivada das ciências naturais, impregnada pela "ansiedade cartesiana" que impõem à racionalidade científica a responsabilidade pelo conhecimento objetivo da natureza, seu controle e dominação em benefício de uma humanidade distante (SANTOS, 2019).

As ciências sociais ocuparam tardiamente o espaço de investigação sobre as questões ambientais (MENESES, 1999; DRUMMOND, 2006; FLEURY; ALMEIDA; PREMEBIDA, 2014) e quando o fizeram, seguiram uma trajetória predominantemente crítica às ciências naturais pela visão restritiva de conservação praticada pelas redes filiadas acusadas de não considerarem as populações que habitam as áreas protegidas ou seu entorno (BERKES, 2017; DIEGUES, 2019).

As epistemologias do Sul, universo teórico e pedagógico proposto por Santos e Meneses (2010), em trabalho colaborativo, chamam atenção para a diversidade de conhecimentos e saberes do mundo e criticam a centralidade do conhecimento científico produzido pelos países do Norte:

É insustentável a situação de, por exemplo, as ciências sociais continuarem a descrever e interpretar o mundo em função de teorias, de categorias e de metodologias desenvolvidas para lidar com as sociedades modernas do Norte, quando a maioria das sociedades existentes não só apresenta características e dinâmicas históricas diferentes, como tem gerado as suas próprias formas de conhecimento das suas experiências sociais e históricas e produzido contribuições significativas para as ciências sociais, ainda que remetidas para as margens destas (SANTOS; MENESES; NUNES, 2005, p. 23).

Arturo Escobar se associa a Boaventura de Sousa Santos ao considerar que as questões afetas à natureza são certamente preocupantes, mas que os problemas vão bem além dos 
domínios epistemológicos das ciências naturais. A partir de um conjunto de discursos em que se cruzam diferentes conhecimentos, culturas e estratégias políticas, Escobar e Pardo (2005) propõem diferentes perspectivas sobre natureza: i) visão "globalocêntrica"; ii) perspectiva nacional do Terceiro Mundo; iii) biodemocracia e; iv) visão da natureza pelos movimentos sociais.

Reconhece-se, desta maneira, a existência de discursos em defesa de uma visão plural de natureza com interfaces à cultura, onde permeia uma vasta rede de comunidades e atores que têm vivenciado práticas e ressignificado o entendimento de conservação da natureza, sobretudo em áreas protegidas criadas no Sul, como no caso da Amazônia (ESCOBAR; PARDO, 2005; ALIMONDA, 2011).

$\mathrm{Na}$ Amazônia os ecossistemas abrigam uma riqueza de natureza e cultura que se impõe diante de manifestações globalocêntricas para pensar e agir enquanto alternativas de conhecimentos e saberes ecológicos que continuam pouco credível à luz das ciências, mas de epistemes presentes nas realidades múltiplas do local (ESCOBAR, 2007; 2011; CASTRO, 2018). São essas ecologias de saberes que constroem a resistência às ameaças à natureza, como no caso das lutas travadas na Amazônia por Chico Mendes, Tomé de Sousa Belo e Pedro Ramos $^{13}$ pela floresta em pé e por direito a terras, se associando ao que Araújo (2016) aclama por ecologia de direitos e de justiças cognitivas.

\section{CONSERVAÇÃO DA NATUREZA NA AMAZÔNIA BRASILEIRA: O CA- SO DO AMAPÁ}

O Amapá é um estado da Amazônia brasileira pouco conhecido aos olhares da ciência, que invariavelmente o descreve como uma região de natureza preservada ou fronteira da preservação (BECKER, 2009), num típico cenário de interpretação ao princípio bíblico da criação da terra do Gênesis e semelhante à paisagem natural descrita pelo frei Gaspar de Carvajal na época da colonização do Brasil (ROSÁRIO; ROSÁRIO, 2018).

Por outro lado, o Amapá também possui uma história vinculada à intensa exploração mineral (manganês), manifesta pela condição geológica que sempre ressurge como única alternativa econômica, sobretudo ouro, ferro e mais recentemente possíveis ocorrências de petróleo e gás em ambiente marinho costeiro. O Amapá traduz literalmente o que Alimonda (2011, p. 52) descreve como "espaço da colonialidade da natureza", com convergências ao entendimento de Svampa (2012, p. 18) em relação ao que denomina de "território sacrificável"14 pelo capitalismo das commodities.

O Amapá tem 73,7\% do seu território transformado em áreas protegidas, com predomínio da tipologia Unidades de Conservação da Natureza e Terras Indígenas ${ }^{15}$ (Tabela 1).

\footnotetext{
${ }^{13}$ Chico Mendes, Tomé de Sousa Belo e Pedro Ramos são lideranças dos povos da floresta que lutaram pela organização e reconhecimento desses grupos quanto ao direito à terra e a viver fora do sistema capitalista dos patrões. Chico foi assassinado em 1998. Tomé faleceu em 2017. Pedro continua na luta. O “empate” era uma ação coletiva organizada pelos seringueiros para o enfretamento ao desmatamento da floresta.

14 Vários estudos atestam que o Amapá se caracteriza como um "território de sacrifício pela mineração", que além dos danos à natureza, também tem deixado um rastro de violência nos corpos e nas vidas das pessoas (BRITO, 1994; MONTEIRO, 2003; CHAGAS, 2013).

15 Gallois (2004, p. 39) explica didaticamente a diferença entre terra e território indígena: "Terra indígena" diz respeito ao processo político-jurídico conduzido sob a égide do Estado, enquanto "território" remete à construção e à vivência, culturalmente variável, da relação entre uma sociedade específica e sua base territorial.
} 
Tabela 1 - Áreas Protegidas no Amapá

\begin{tabular}{|c|c|c|}
\hline Área Protegida & Hectares & $\begin{array}{c}\text { \% em relação à superfície do } \\
\text { Amapá }\end{array}$ \\
\hline Unidade de Conservação Federal & 6.199 .054 & 43,4 \\
\hline Unidade de Conservação Estadual & 3.197 .507 & 22,4 \\
\hline Terras Indígenas & 1.125 .671 & 7,9 \\
\hline Total & 10.522 .232 & 73,7 \\
\hline
\end{tabular}

Fonte: Gallois e Grupioni (2003); Chagas (2015).

A criação de áreas protegidas no Amapá remonta às décadas de 1970/1980, quando o governo da ditadura militar anunciava a integração regional e projetava cenários desenvolvimentistas que ameaçavam a integridade dos ecossistemas e das comunidades indígenas, sobretudo pela abertura de estradas e pelo incentivo a atividades de mineração. Por constituir um "território ocioso" (SVAMPA, 2012, p. 27) e de ambientes naturais praticamente intocados, o Amapá foi transformado numa grande área protegida, abrangendo cerca de 10 milhões de hectares, entre Unidades de Conservação da Natureza e Terras Indígenas.

Ações de conservação da natureza se intensificaram no Amapá nos anos 1990 com o apoio do componente de Parques e Reservas do Programa Piloto para a Proteção das Florestas Tropicais do Brasil (PPG-7). ${ }^{16}$ O Ministério do Meio Ambiente, em 1999, realizou na cidade de Macapá, no estado do Amapá, o workshop “Áreas Prioritárias para a Conservação da Biodiversidade da Amazônia”. O evento proporcionou que cientistas naturais mapeassem áreas de maior importância para a conservação da biodiversidade na região.

Como resultado desse processo, um conjunto de áreas protegidas passou a ser criado na região conhecida como Calha Norte do Rio Amazonas e Escudo das Guianas. Essas áreas totalizam cerca de 20.000.000 de hectares de territórios especialmente protegidos. Constitui um dos maiores blocos contínuos de floresta tropical do planeta, considerado de extrema importância para a conservação da biodiversidade (BRASIL, 2001), com destaque para o Parque Nacional Montanhas do Tumucumaque, o maior do planeta em área de floresta tropical (CHAGAS, 2008) (Figura 1 e Tabela 2).

16 O PPG-7 foi um programa de cooperação internacional pactuado na ECO-92 e executado nos anos 1990, tendo como doador líder a Alemanha. Suas ações foram voltadas para o combate às principais causas do desmatamento nas florestas tropicais brasileiras. Um dos objetivos específicos do PPG-7 era a proteção da biodiversidade por meio da criação de Parques e Reservas na Amazônia. 
Figura 1 - Áreas Protegidas Amapá-Pará, com destaque para o Parque Nacional Montanhas do Tumucumaque (em verde)

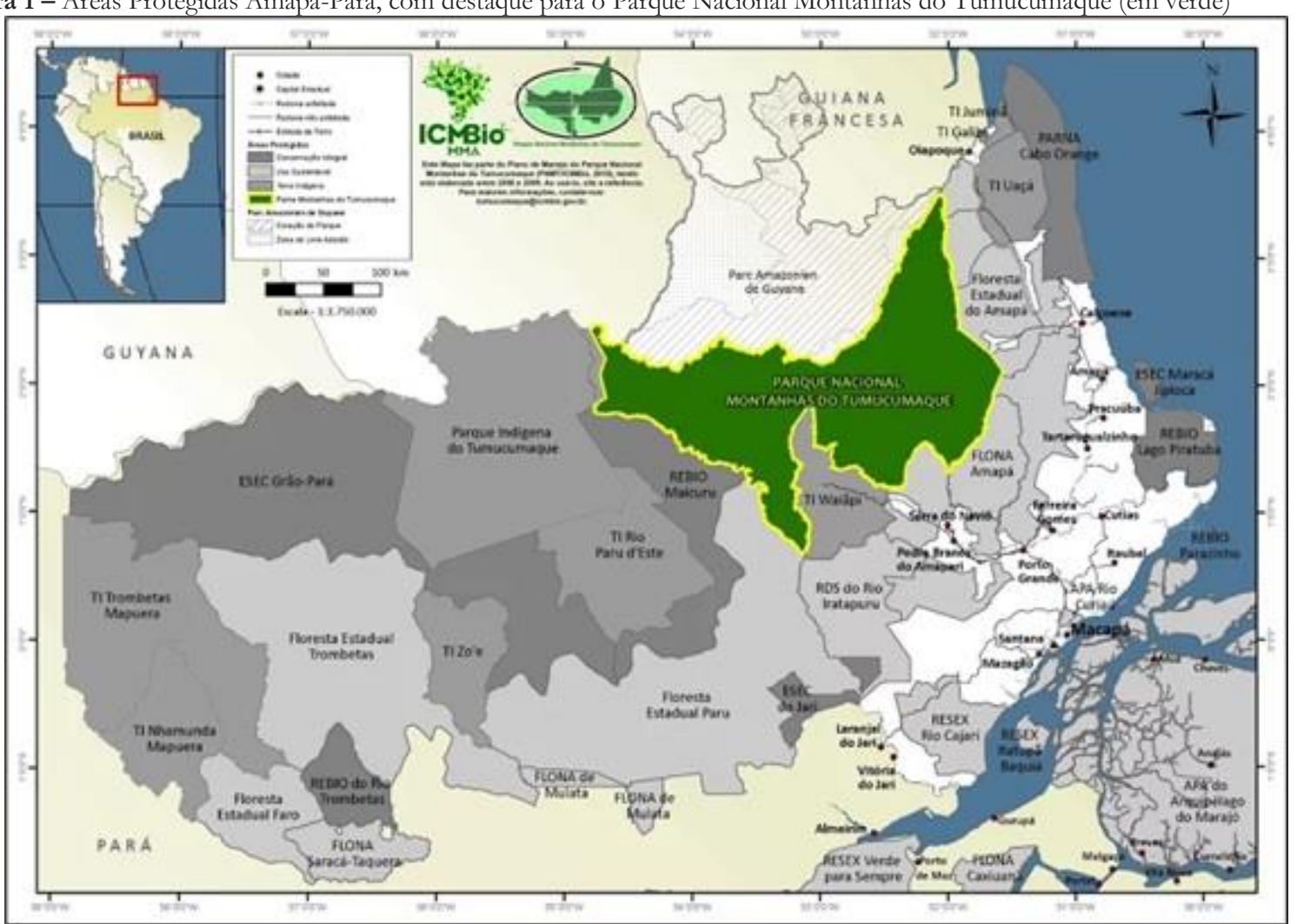

Fonte: ICMBio (2009).

Tabela 2 - Áreas protegidas da Calha Norte do Rio Amazonas e Escudos das Guianas

\begin{tabular}{clc}
\hline Região & \multicolumn{1}{c}{ Área Protegida } & Hectares \\
\hline Amapá & Parque Nacional Montanhas do Tumucumaque & 3.846 .400 \\
\hline \multirow{4}{*}{ Pará } & Estação Ecológica do Grão Pará & 4.245 .800 \\
\cline { 2 - 3 } & Floresta Estadual do Paru & 3.612 .900 \\
\cline { 2 - 3 } & Floresta Estadual do Trombetas & 3.172 .900 \\
\cline { 2 - 3 } & Reserva Biológica Maicuru & 1.151 .700 \\
\cline { 2 - 3 } & Floresta Estadual do Faro & 613.800 \\
\hline Guiana Francesa & Parque Natural Regional da Guiana & 3.390 .000 \\
\hline \multicolumn{1}{c}{ Total } & $\mathbf{2 0 . 0 3 3 . 5 0 0}$ \\
\hline
\end{tabular}

Fonte: Organizado pelo autor.

A partir de 2002, com o objetivo de desmistificar o slogan de "áreas protegidas no papel” e abri-las ao acesso público, foi criado o Programa Áreas Protegidas da Amazônia (ARPA). Uma iniciativa de longo prazo (2002-2039) do Governo Federal brasileiro, coordenada pelo Ministério do Meio Ambiente (MMA), com recursos de cooperação internacional. Trata-se do maior programa de cooperação para áreas protegidas do planeta e indicado por Wilson (2019) como impulso para o alcance da meta de proteger 50\% da terra em espaços reservados.

O ARPA apoia a criação e a elaboração de planos de manejo/gestão de áreas protegidas na Amazônia, com importantes aportes para as metas vinculadas à Convenção sobre Diversidade Biológica (CDB). O recurso do ARPA é a principal fonte de financiamento para as áreas protegidas da Amazônia, implicando em preocupações com a sustentabilidade financeira pós-ARPA, principalmente diante de contextos de governos politicamente desfavoráveis à conservação. 
As lições aprendidas no ARPA necessitam ser traduzidas em conquistas e lutas para o não retrocesso. Antes do ARPA, experiências de implantação comunitária de áreas protegidas eram raras, o que fragilizava qualquer articulação voltada para a conservação da natureza fora do modelo de áreas protegidas concebido segundo a ideia de wilderness do imaginário norteamericano e reaplicado para os países do Sul (JUNQUEIRA, 2001; SANTOS, MENESES, NUNES, 2005, p. 65).

Irving (2006), por exemplo, distancia-se da ecologia sagrada para propor a criação de uma Reserva de Biosfera Transfronteiriça na Amazônia, com núcleos no Parque Nacional Montanhas de Tumucumaque no Brasil e outro no Parque Nacional Regional da Guiana na Guiana Francesa, num exercício efetivo de política de cooperação binacional voltada para conservação integrativa - natureza e cultura.

A conservação da natureza na Amazônia precisa se conciliar com as práticas da ecologia de saberes se pretende resistir ao racismo oficial que desinstitucionaliza a gestão dos espaços protegidos para favorecer aos interesses do capitalismo. Acselrad (2014) destaca que, diante dos conflitos provocados pelas ameaças e impactos aos territórios habitados pelos povos da floresta, o pensamento crítico da ciência se manifesta por diferentes estratégias de conhecimentos em disputa, mas destaca que os saberes cognitivos, por vezes tidos como leigos, devem situar politicamente o que realmente importa e o que tem valor.

\section{AMEAÇAS À CONSERVAÇÃo DA NATUREZA E À ECOLOGIA DE SA- BERES}

Casos de ameaças à conservação da natureza e aos povos da floresta pelo capitalismo das commodities acontece desde que o Brasil foi colonizado pelos Europeus e tem se intensificado na Amazônia nas últimas décadas, com implicações que passam pela tolerância perigosa à resiliência dos ecossistemas, mas sobretudo por conflitos que se manifestam pelas dores dos outros, as quais a ciência e o direito tradicional são apenas reativos.

Dois casos na Amazônia brasileira são aqui relatados de modo a provocar alguma reflexão sobre formas de ameaças, ainda como alerta, mas que de certa forma filia-se à rede que se conecta em diferentes contextos da institucionalidade acadêmica de retaguarda ${ }^{17}$ e em alternativas comunicativas de apoio aos grupos sociais a serem afetados (FERNANDES; BARCA, 2012; ASCELRAD, 2014; BRAVIN; FERNANDES, 2017; SANTOS, 2019; PINTO, 2020).

O primeiro caso se refere à possível exploração de petróleo em áreas próximas à existência de recifes de corais na Foz do Amazonas (Figura 2); o segundo diz respeito a articulação política em curso para a extinção da Reserva Nacional do Cobre e Associados (RENCA) e liberação da área para a exploração mineral. A RENCA está superposta a um dos mais importantes mosaicos de conservação da natureza da Amazônia (Figura 3).

A exploração de petróleo na bacia da Foz do Amazonas encontra-se em processo de licenciamento ambiental pelo governo federal brasileiro, ora adormecido pela sensatez quanto à inviabilidade ambiental da atividade, ora impulsionado pelos ideais de salvacionismo capitalista de interesse político, sob o discurso desenvolvimentista colonial que se reproduz na

\footnotetext{
17 Santos (2019) questiona o papel do intelectual da academia quanto ao seu papel de vanguarda junto aos movimentos sociais, argumentando que deve ser de retaguarda no sentido de resguardar princípios da democracia comunitária e de construir conhecimentos híbridos na retaguarda desses movimentos.
} 
Amazônia a cada ciclo de governos.

A evolução geológica correlata à costa africana e a proximidade da Guiana Francesa, onde existem campos petrolíferos em produção, indicam que a região marítima do Amapá possui alta probabilidade de ocorrência de petróleo e gás com viabilidade econômica, segundo análise dos estudos ambientais elaborados sob os auspícios das empresas interessadas. ${ }^{18}$

A descoberta de recifais nas proximidades dos blocos de petróleo chamou atenção pela representatividade espacial e diversidade de espécies (RALF et al., 2015; MOURA et al., 2016; MAHIQUES et al., 2019). A região costeira amapaense abrigar um conjunto de áreas protegidas que garantem a conservação de ecossistemas frágeis, como os manguezais, que conectam uma intricada rede de relação ecológica terra-mar, responsável pela segurança alimentar de um conjunto de populações que vive da pesca (SANTOS; MENDES; SILVEIRA, 2016).

Figura 2 - Localização dos recifes de corais da foz do Rio Amazonas e dos blocos exploratórios de petróleo

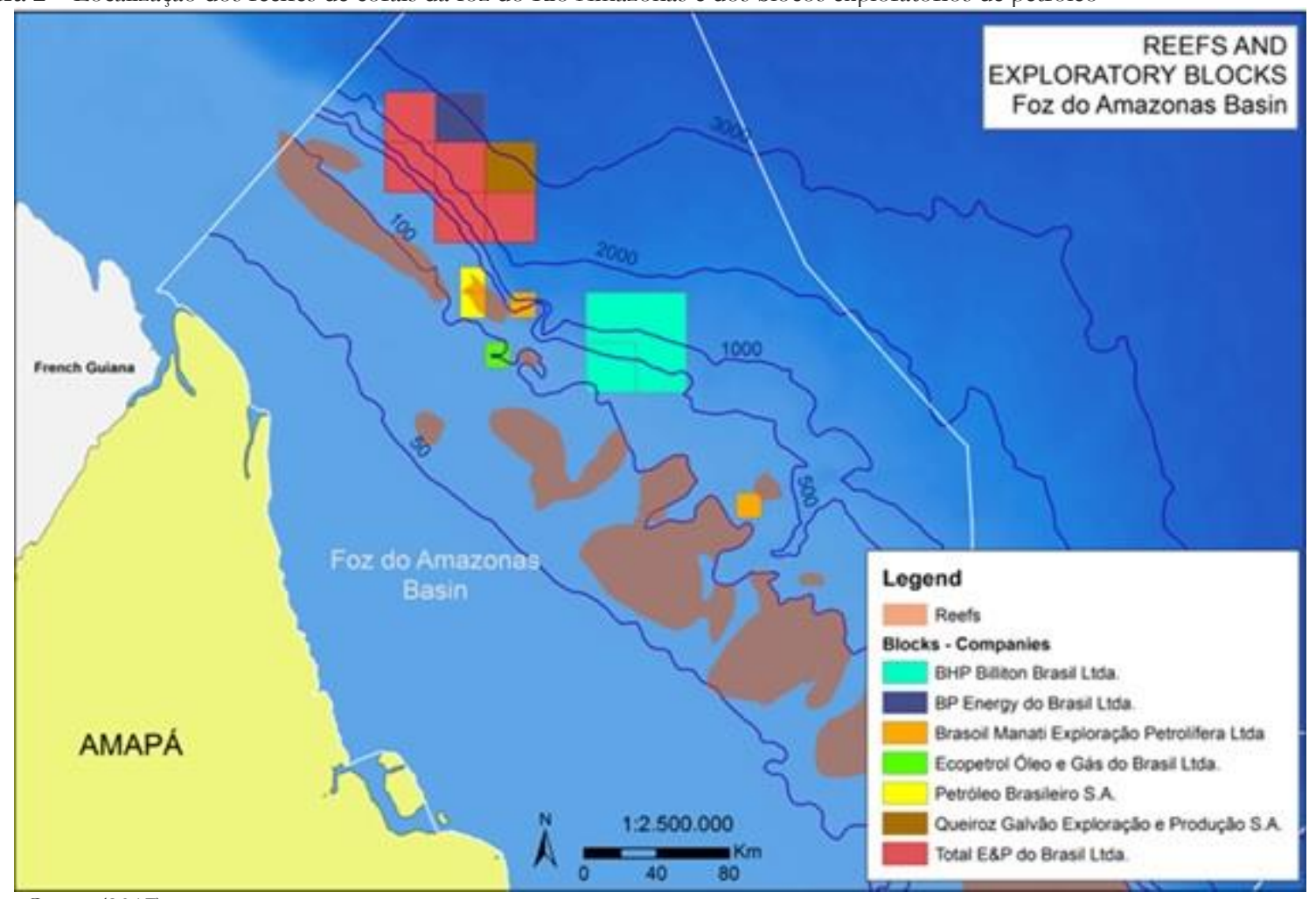

Fonte: Carter (2017).

O outro caso reporta-se à RENCA, uma área criada em 1984 como reserva mineral estratégica, com 4,6 milhões de hectares, equivalente à metade da área de Portugal, localizada entre o Amapá e o Pará, em pleno domínio da floresta amazônica, onde existe um mosaico de 20 milhões de hectares de áreas protegidas, constituindo um dos maiores corredores de diversidade biocultural do planeta (CHAGAS et al., 2017).

Em agosto de 2017, o governo federal ameaçou extinguir a RENCA e liberar a área para investimentos privados de mineração, o que motivou protestos e manifestações de movi-

${ }^{18} \mathrm{Um}$ dos problemas relativos à elaboração dos estudos ambientais é a sua contratação direta pela empresa a ser licenciada. Vários países vêm aperfeiçoando esse processo, de modo a minimizar parcialidades. 
mentos socioambientais, conectados em diferentes escalas (local, nacional, global), em favor da conservação da natureza e das garantias constitucionais de proteção dos territórios indígenas.

Figura 3 - Localização da Reserva Nacional do Cobre e Associados (RENCA) - entre os estados do Amapá Pará, Amazônia brasileira

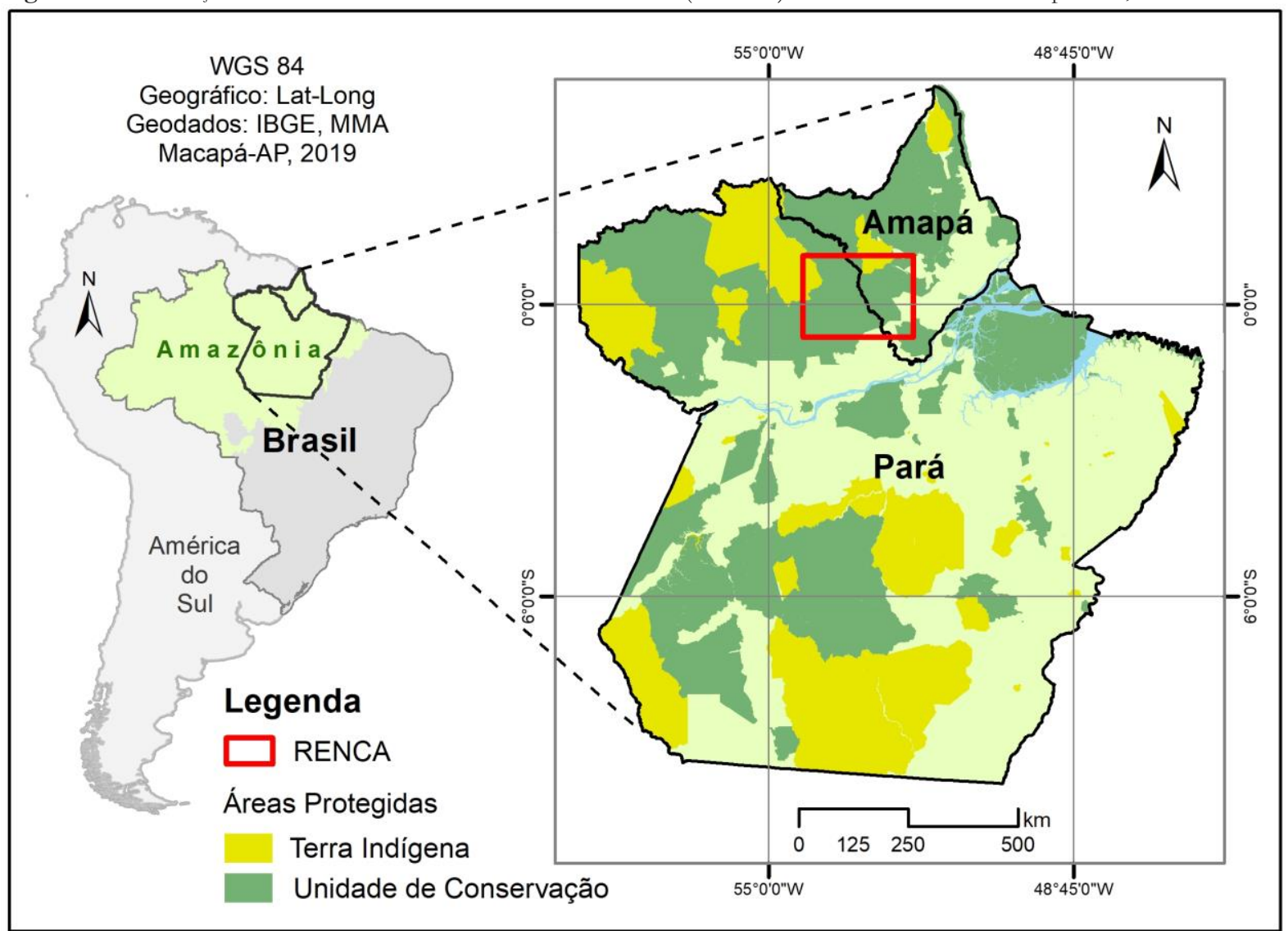

Fonte: Elaborado pelo geógrafo Jodson Cardoso de Almeida (2019).

Os casos citados incitam uma profunda discussão sobre a lógica capitalista e as desigualdades socioambientais que são invisibilizadas pelos interesses mais imediatistas, para os quais Acselrad et al. (2012, p. 165) têm alertado:

[...] o capitalismo liberalizado faz com que os danos decorrentes de práticas poluentes recaiam predominantemente sobre grupos sociais vulneráveis, configurando uma distribuição desigual dos benefícios e malefícios do desenvolvimento econômico. Basicamente, os benefícios destinam-se a grandes interesses econômicos e os danos a grupos sociais despossuídos.

A exploração de petróleo e de minérios no Amapá afeta grupos indígenas, pescadores artesanais e outros grupos sociais que têm na natureza a representação de territórios protegidos, modos de vida e de sustento. ${ }^{19}$ Esses grupos são colocados às margens das decisões políticas e muitas vezes vistos como "ignorantes" por discordarem do desenvolvimento proposto unicamente pelo capitalismo das commodities. Portanto, se reposicionam em lutas por 19 Os impactos causados pelo derramamento de petróleo no mar são irreversíveis e de alta significância. A maioria das
empresas do setor não dispõe de brigadas estruturadas para lidar com esse tipo de impacto. 
direitos cognitivos fora das tênues instituições de Estado e do próprio conhecimento científico (ACSELRAD, 2014).

Escobar (2005) reconhece a capacidade de grupos sociais interpelarem o poder e de articularem redes de resistência para o enfrentamento das assimetrias que instruem a lógica da apropriação de recursos naturais na Amazônia. O autor entende que existe uma marginalização desses grupos locais pelo capitalismo e propõe repensar conceitos, como "lugar":

Poder-se-ia discutir que -apesar da necessidade de revisar os conceitos e categorias convencionais do local- o lugar e o conhecimento baseado no lugar, continuam sendo essenciais para abordar a globalização, o pós-desenvolvimento e a sustentabilidade ecológica, de formas social e politicamente efetivas (ESCOBAR, 2005, p. 71).

Silva (2016, p. 178), com fundamentos em Escobar (2001), acrescenta que a descolonização epistêmica ao desenvolvimento pelo consenso das commodities passa pela autoafirmação das lutas originadas localmente, pois “o mercado não tem um senso de lugar”.

\section{CONSERVAÇÃO DA NATUREZA E ECOLOGIA DE SABERES EM COMPLEMENTARIDADE}

Na Amazônia, a gestão das áreas protegidas criadas pelo Estado ${ }^{20}$ segue a visão globalocêntrica de natureza associada ao conceito de biodiversidade (CHAGAS, 2009, p. 185). Entretanto, no dia a dia, os sujeitos das instituições públicas responsáveis pela gestão da conservação da natureza têm vivenciado experiências e práticas que conectam o conhecimento científico a outros saberes, percebidos a partir de um aprendizado socialmente construído, e isso tem permitido o surgimento de novas estratégias, muitas das quais afirmadas em estatutos próprios. ${ }^{21}$

Individualizar essas experiências na diversidade ou pluriversidade amazônica é reconhecer o exercício de injustiças e de omissões, as quais este escrito se faz por assumir, mesmo diante de narrativas e outras vivências que têm sido comunicadas em publicações científicas, planos e protocolos que se propõem a interpretar práxis socioambientais coletivas. Essas ausências não significam que não existam produções credíveis sobre o tema, mas sim que ainda carecem de uma "escuta profunda" para ouvir a si mesmo e então controlar o monopólio das metodologias científicas para ofertar outros aportes epistemológicos (SANTOS, 2019).

Uma das mais exitosas experiências ou práxis em área protegida na Amazônia é a das Reservas Extrativistas. Trata-se de uma construção social de políticas públicas a partir de lutas de cientistas naturais, cientistas sociais e principalmente das populações tradicionais que "vivem com a floresta", sob a liderança de Chico Mendes.

Esta política - de criação de áreas protegidas para o uso sustentável de populações tradicionais - foi exitosa politicamente, porque criou um mecanismo institucional de resolução de conflitos em torno da terra e da floresta; socialmente, porque assegurou meios de vida para as gera-

\footnotetext{
${ }^{20}$ No Brasil, as áreas protegidas são gerenciadas pelo Instituto Chico Mendes de Conservação da Biodiversidade (ICMBio).

21 Programa de Zoneamento Ecológico-Econômico, Plano Estratégico Nacional de Áreas Protegidas, Plano de Manejo de Unidades de Conservação, Plano de Gestão Territorial de Terras Indígenas, Protocolo de Consulta de Povos Indígenas, entre outros.
} 
ções atuais e futuras; culturalmente, porque respeitou formas tradicionais de uso dos recursos naturais; e ambientalmente, porque impediu o avanço dos desmatamentos (ALLEGRETTI, 2002, p. vii).

As Reservas Extrativistas traduzem a ecologia política da conservação da natureza ao reconhecer a luta dos povos da floresta pelo direito à ocupação de territórios coletivos. Os moradores dessas áreas reivindicam o trabalho livre de hierarquias patronais do aviamento (escravidão por dívida), o agroextrativismo como prática socioeconômica de baixo impacto e a valorização da floresta em pé enquanto patrimônio intergeracional (ALLEGRETTI, 2002, FILOCREÃO, 2007; RANGEL, 2017).

As populações locais, cuja cooperação depende o sucesso da conservação da natureza, são elos de uma complexa teia que se movimenta diante de ameaças, como nos casos aqui relatados. Assim, os estatutos que regram as áreas protegidas tem prazo de validade que se expira na medida da necessidade de novos arranjos de proteção jurídica, mas também de contraataque em busca de novos direitos.

Os estatutos dos planos de manejo das áreas protegidas criadas na Amazônia, por exemplo, retratam encontros e desencontros entre os roteiros institucionais programáticos e a diversidade cultural. De certa forma, esses planos demonstram potencial para rediscutir perspectivas voltadas para a conservação da natureza de maior intensidade.

No caso do Parque Nacional Montanhas do Tumucumaque, no Amapá, os pesquisadores que estudaram as questões indígenas e as populações locais para subsidiar a elaboração do plano de manejo da unidade, demonstraram que a conservação da natureza é mais complexa do que sugere o paradigma dominante e que existem ações alternativas emergentes, como a formação de mosaicos integrados de áreas protegidas com protagonismo dos grupos indígenas, herdeiros ancestrais da terra, além das populações que de alguma forma vivem com a floresta (MARETTTI, 2004; ICMBIO, 2009).

Os mosaicos de áreas protegidas criados no Brasil, ao inserirem as terras indígenas, a exemplo do "Mosaico Oeste do Amapá e Norte do Pará", dão sentido ao significado de "artesanias das práticas”, conforme proposto por Santos (2019, p. 61-63). As artesanias das práticas dos mosaicos, ao integrar as Terras Indígenas a outros espaços protegidos, potencializam estratégias de lutas coletivas contra as ameaças de destruição da natureza.

As Terras Indígenas são elos para a conservação da natureza e nunca é demais lembrar que os indígenas não foram enquadrados pelo Sistema Nacional de Unidades de Conservação (SNUC) e isso de certa forma alivia a sempre tensa relação com o Estado. Santilli (2005), ao explicar que os direitos indígenas são originários e anteriores à criação do Estado, vai além ao destacar a importância desses territórios para a conservação da sociobiodiversidade.

Por sua vez, Almeida, Allegretti e Postigo (2018) destacam as Reservas Extrativistas como o principal legado de Chico Mendes e resgatam citação de Lévi-Strauss (2003) para reafirmar os argumentos deste artigo com relação a gestão integrada de áreas protegidas em mosaicos: "ao lado das Terras Indígenas, as Reservas Extrativistas poderiam constituir a melhor esperança para salvar a Amazônia, ao mesmo tempo em que destacou a originalidade do conceito".

Outro exemplo no Amapá que permite revisitar o conceito de conservação da natureza vem dos acordos de pesca firmados entre os pescadores da vila do Sucuriju ${ }^{22}$ e a instituição

22 Vila de pescadores localizada na costa do estado do Amapá, que já fez parte da Reserva Biológica do Lago Piratuba e

PRACS: Revista Eletrônica de Humanidades do Curso de Ciências Sociais da UNIFAP https://periodicos.unifap.br/index.php/pracs ISSN 1984-4352 Macapá, v. 13, n. 2, p. 341-360, jul./dez. 2020 
responsável pela gestão da Reserva Biológica do Lago Piratuba para dirimir conflitos da pesca nos lagos da reserva legalmente intocável. Os acordos são manifestações explícitas de alternativas de conservação da natureza que têm favorecido o diálogo entre o órgão público gestor da reserva e os pescadores sobre o controle territorial da área, principalmente diante da intensa dinâmica natural e social que envolve a vida dos pescadores da comunidade do Sucuriju (SAUTCHUK, 2007).

Os planos de manejo de áreas protegidas, quando avaliados pela ótica dos valores e da cultura de quem pratica a conservação da natureza para além da visão globalocêntrica, são processos adaptativos que moldam o território de acordo com conhecimentos, saberes e práticas.

As experiências de gestão de áreas protegidas sinalizam que a conservação da natureza mantém relação com um conjunto de manifestações de conhecimentos e saberes que aproximam cientistas naturais, cientistas sociais e populações locais. Referidos diálogos são necessários em resposta à complexa rede com que se defrontam as diferentes interpretações de natureza e seus rebatimentos quanto a desmistificar o imaginário coletivo, ainda dominante, de território ocioso a ser sacrificado, como no caso da Amazônia.

\section{CONSIDERAÇÕES FINAIS}

Natureza é um conceito de derivação das ciências naturais, mas que tem se aproximado das ciências sociais em busca de reconhecimentos que se designam como consilientes, na proposição do naturalista Edward Wilson, ou alternativos de ecologia de saberes a partir das experiências do Sul, conforme sustentam os aportes teóricos de Arturo Escobar e Boaventura de Sousa Santos.

$\mathrm{Na}$ visão consiliente de conservação de natureza proposta por Wilson, as áreas protegidas devem ser mantidas intocadas para garantir a estabilidade dos sistemas ecológicos e da vida humana. Escobar e Santos corroboram argumentos em favor de diferentes significados de natureza, propõem pesquisas a partir de saberes ecológicos resilientes desprovidos de estereótipos e de enquadramentos teoricamente consensuados por comunidades científicas que representam o conhecimento muitas vezes fora do "lugar".

As Terras Indígenas e as Reservas Extrativistas são espaços estabelecidos em reconhecimento ao direito de populações da floresta a territórios ancestrais e tradicionalmente ocupados. São conquistados em processos de lutas sociais coletivas e que se mantêm ainda fora do campo da visão utilitarista da natureza, apesar da intricada rede de representações políticas que se movimentam em torno de diferentes discursos de mesma face: economia verde, bioeconomia, serviços ambientais, desenvolvimento sustentável, entre outros neologismos da modernidade capitalista.

As experiências de elaboração de planos de manejo das áreas protegidas na Amazônia têm evidenciado outros significados de conservação da natureza fora dos vínculos regulatórios estatais ou dos modelos Yellowstone Park, como no caso da cogestão ou gestão compartilhada em mosaicos territoriais com inclusão de Terras Indígenas e Reservas Extrativistas. Referidas artesanias das práticas de gestão devem ser assumidas como processos ontológicos, entrelaçados de expectativas de direitos cognitivos para uma transição libertária (ESCOBAR, 2015).

O estado do Amapá, localizado ao Norte da Amazônia brasileira, traduz uma das princi-

depois foi excluída pelos pressupostos da conservação da biodiversidade apartada de gente.

PRACS: Revista Eletrônica de Humanidades do Curso de Ciências Sociais da UNIFAP https://periodicos.unifap.br/index.php/pracs ISSN 1984-4352 Macapá, v. 13, n. 2, p. 341-360, jul./dez. 2020 
pais referências conflituosas de políticas de Estado que transformam extensos territórios em espaços protegidos e que, sob qualquer sinalização de exploração de recursos naturais pelo capitalismo, impõe à natureza, aos territórios indígenas e tradicionais uma condição de sacrifício.

Entretanto, os saberes ecológicos dos povos da floresta sinalizam que a conservação da natureza apresenta diferentes dimensões e que invariavelmente a ciência, natural e social, ao contribuir com a tradução intercultural desses saberes, também está engajada na ressignificação de protocolos e apoiando lutas coletivas em defesa das áreas protegidas em mosaicos.

As epistemologias do Sul, literatura densa, crítica e reflexiva, ofertam um universo teórico-pedagógico que ajudam a ir além do conhecimento científico dito credível que vive de suas arrogâncias e verdades. Entre as ferramentas conceituais, as artesanias das práticas ampliam o entendimento sobre o cuidado "artesanal" com a natureza e então possibilitam perceber que a conservação da natureza em áreas protegidas é uma das estratégias para combater a exclusão social e as assimetrias instrumentalizadas pelo capitalismo das commodities.

\section{REFERÊNCIAS}

ACSELRAD, H. Disputas cognitivas e exercício da capacidade crítica: o caso dos conflitos ambientais no Brasil. Sociologia, Porto Alegre, a. 16, n. 35, p. 84-105, 2014.

ACSELRAD, H. et al. Desigualdade ambiental e acumulação por espoliação: o que está em jogo na questão ambiental? e-cadernos CES 17, p. 164-183, 2012. Disponível em: https://journals.openedition.org/eces/1138. Acesso em 29 jan. 2020.

ALIMONDA, H. (coord.) La Naturaleza Colonizada: ecología política y minería em América Latina. Buenos Aires: Clacso; Ediciones Ciccus, 2011.

ALLEGRETTI, M. H. A construção social de políticas ambientais: Chico Mendes e os movimentos seringueiros. 2002. 827f. Tese (Doutorado em Desenvolvimento Sustentável) Centro de Desenvolvimento Sustentável, Universidade de Brasília, Brasília, 2002.

AlmeidA, M. B.; AllegretT'T, M. H.; POSTIGO, A. O legado de Chico Mendes: êxitos e entraves das Reservas Extrativistas. Desenvolvimento e Meio Ambiente, v. 48, Edição especial: 30 Anos do Legado de Chico Mendes, p. 25-55, 2018.

ARAÚJO, S. O primado do direito e as exclusões abissais: reconstruir velhos conceitos, desafiar o cânone. Sociologias, Porto Alegre, a. 18, n. 43, p. 88-115, 2016.

BECKER, B. K. Amazônia: geopolítica na virada do III milênio. Rio de Janeiro: Garamond, 2009.

BENSUSAN, N. (org.). Seria melhor mandar ladrilhar? Biodiversidade: como, para quê e por quê. 2. ed. São Paulo: Pierópolis; Brasília: Ed. UnB, 2008.

BERKES, F. Sacred Ecology. 4. New York: Routledge, 2017.

BRASIL. Avaliação e identificação de ações prioritárias para a conservação, utilização sustentável e repartição dos benefícios da biodiversidade na Amazônia brasileira. Brasília: MMA/SBF, 2001.

BRAVIN, A.; FERNANDES, L. (orgs.). "Diferentes formas de dizer não": expressões de conflitos ambientais de mineração e petróleo em Portugal e na América do Sul. Cescontexto - Debates, n. 17, maio 2017. Disponível em: http://www.ces.uc.pt/publicacoes/cescon texto/ficheiros/cescontexto_debates_xvii.pdf. Acesso em: 30 jan. 2020.

BRITO, D. C. Extração mineral na Amazônia: a experiência da exploração de manganês 
da Serra do Navio no Amapá. 1994. Dissertação (Mestrado em Planejamento do Desenvolvimento) - Núcleo de Altos Estudos Amazônicos, Universidade Federal do Pará, Belém, 1994.

CARTER, L. Amazon reef: BP and Total set to drill for oil near newly discovered coral reef. Unearthed, Greenpeace, 30 jan. 2017. Disponível em: https://unearthed.greenpeace.org/ 2017/01/30/amazon-reef-mouth-bp-total-oil-drilling/. Acesso em: 14 fev. 2020.

CASTRO, E. Epistemologias e Caminhos da Crítica Sociológica Latino-Americana. In: CASTRO, E.; PINTO, R. F. (org.). Decolonialidade e Sociologia na América Latina. Belém: NAEA, 2018. p. 25-52.

CASTRO, E. V. Outros valores, além do frenesi de consumo. Entrevista concedida em 20/09/2012 a Júlia Magalhães. Disponível em: https://outraspalavras.net/semcategoria/outros-valores-alem-do-frenesi-de-consumo/. Acesso em: 22 jul. 2019.

CHAGAS, M. A. Tumucumaque: o "Big Park" e a História do Conservacionismo no Amapá. Rio de Janeiro: Ed. do Autor, 2008.

CHAGAS, M. A. Amapá: a mineração e o discurso da sustentabilidade - de Augusto Antunes a Eike Batista. Rio de Janeiro: Garamond, 2013.

CHAGAS, M. A. Uma Contribuição ao Conhecimento da História de Criação das Unidades de Conservação do Amapá - Amazônia Brasileira. Sustentabilidade em Debate, Brasília, v. 6, n. 2, p. 211-227, 2015.

CHAGAS, M. A. et al. A articulação entre o complexo verde de Ab'Saber e o complexo urbano de Becker como desafio do desenvolvimento regional: Amapá como um caso amazônico. Revista Brasileira de Pós-Graduação, v. 13, n. 32, p. 829-860, 10 mar. 2017.

COUTO, M. E se Obama fosse africano? São Paulo: Companhia das Letras, 2016.

DIEGUES, A. C. Conhecimentos, Práticas Tradicionais e Etnoconservação da Natureza.

Revista Desenvolvimento e Meio Ambiente, v. 50, p. 116-126, 2019.

DRUMMOND, J. A. A Primazia dos Cientistas Naturais na Construção da Agenda Ambiental Contemporânea. Revista Brasileira de Ciências Sociais, v. 21, n. 62, out. 2006.

EHRLICH, P. A Perda da Diversidade: Causas e Consequências. In: WILSON, E. (org.). Biodiversidade. São Paulo: Editora Nova Fronteira, 1997.

ESCOBAR, A. Whose Knowledge, Whose nature? Biodiversity, Conservation, and the Political Ecology of Social Movements. Journal of Political Ecology, v. 5, 1998.

ESCOBAR, A. O lugar da natureza e a natureza do lugar: globalização ou pósdesenvolvimento? In: LANDER, E. (org.). A colonialidade do saber: eurocentrismo e ciências sociais. Perspectivas latino-americanas. Colección Sur Sur. Buenos Aires: CLACSO, 2005. Disponível em: http://bibliotecavirtual.clacso.org.ar/clacso/sur-sur/201006241021 40/8_Escobar.pdf. Acesso em: 10 jan. 2020.

ESCOBAR, A. La Invención del Tercer Mundo: Construcción y deconstrucción del desarrollo. Venezuela: Fundación Editorial el Perro y la Rana, 2007.

ESCOBAR, A. Ecología Política de la Globalidad y la Diferencia. In: ALIMONDA, H. (coord.) La Naturaleza Colonizada: ecología política y minería em América Latina. Buenos Aires: Clacso; Ediciones Ciccus, 2011.

ESCOBAR, A. Territorios de diferencia: la ontología política de los "derechos al territorio". Desenvolvimento e Meio Ambiente, v. 35, p. 89-100, 2015.

ESCOBAR, A.; PARDO, M. Movimentos sociais e biodiversidade no Pacífico colombiano. In: SANTOS, B. S. (org.). Semear Outras Soluções: os caminhos da biodiversidade e dos 
conhecimentos rivais. Rio de Janeiro: Civilização Brasileira, 2005.

FERNANDES, L.; BARCA, S. (orgs.). Desigualdades ambientais: conflitos, discursos, movimentos. e-cadernos CES, 17, 2012. Disponível em: https://journals.openedition.org/ eces/1092. Acesso em: 08 jan. 2020.

FILOCREÃO, A. S. M. Agroextrativismo e capitalismo na Amazônia: as transformações recentes no agroextrativismo do Sul do Amapá. 2007. 541f. Tese (Doutorado em Desenvolvimento Socioambiental) - Núcleo de Altos Estudos Amazônicos, Universidade Federal do Pará, Belém, 2007.

FLEURY, L. C.; ALMEIDA, J.; PREMEBIDA, A. O ambiente como questão sociológica: conflitos ambientais em perspectivas. Sociologia, Porto Alegre, a. 16, n. 35, p. 34-82, 2014.

FOSTER, J. B. A ecologia de Marx: materialismo e natureza. Rio de Janeiro: Civilização Brasileira, 2005.

FRANCO, J. L. A. O conceito de biodiversidade e a história da biologia da conservação: da preservação da wilderness à conservação da biodiversidade. História, São Paulo, v. 32, n. 2, p. 21-48, 2013.

GALLOIS, D. T. Terras ocupadas? Territórios? Territorialidades? In: RICARDO, F. (org.). Terras Indígenas \& Unidades de Conservação da natureza: o desafio das sobreposições. São Paulo: Instituto Socioambiental, 2004. Disponível em: https://acervo.socioambi ental.org/acervo/publicacoes-isa/terras-indigenas-unidades-de-conservacao-da-natureza-odesafio-das. Acesso em: 22 jan. 2020.

GAllois, D. T.; GRUPIONI, D. F. Povos Indígenas no Amapá e Norte do Pará: quem são, onde estão, quantos são, como vivem e o que pensam? São Paulo: Iepé, 2003.

ICMBio. Plano de Manejo do Parque Nacional Montanhas do Tumucumaque. Brasília: ICMBio; Ministério do Meio Ambiente, 2009.

IRVING, M. A. Áreas Protegidas de Fronteira e Turismo Sustentável na Amazônia: entre o Surrealismo e a Invenção. Revista de Desenvolvimento Econômico, a. VIII, n. 13, 2006. JUNQUEIRA, M. A. Representações políticas do território latino-americano na Revista Seleções. Revista Brasileira de História, São Paulo, v. 21, n. 42, p. 323-342, 2001.

KRENAK, A. Ideias para adiar o fim do mundo. São Paulo: Companhia das Letras, 2019. QUIJANO, A. Colonialidade do poder, eurocentrismo e América Latina. In: LANDER, Edgardo (org.). A colonialidade do saber: eurocentrismo e ciências sociais. Perspectivas latino-americanas. Colección Sur Sur, Buenos Aires: CLACSO, 2005. Disponível em: http:// biblioteca.clacso.edu.ar/clacso/sur-sur/20100624103322/12_Quijano.pdf. Acesso em: 02 fev. 2020.

MAHIQUES, M. M. et al. Insights on the evolution of the living Great Amazon Reef System, equatorial West Atlantic. Scientific Reports. 9:13699, 2019.

MARETTI, C. Conservação e valores - Relações entre áreas protegidas e indígenas: possíveis conflitos e soluções. In: RICARDO, F. (org.). Terras Indígenas \& Unidades de Conservação da natureza: o desafio das sobreposições. São Paulo: Instituto Socioambiental, 2004. Disponível em: https://acervo.socioambiental.org/acervo/publicacoes-isa/terrasindigenas-unidades-de-conservacao-da-natureza-o-desafio-das. Acesso em: 22 fev. 2020.

MENESES, M. P. A natureza, a biodiversidade e o conhecimento local: qual o papel dos cientistas sociais? Estudos Moçambicanos, 17, 1999. p. 257-276.

MENESES, M. P. Memórias de violências: Que futuro para o passado? Revista Crítica de Ciências Sociais, 106, 2015. 
MENESES, M. P. Colonialismo como violência: a "missão civilizadora" de Portugal em Moçambique. Revista Crítica de Ciências Sociais, n. spe., nov. 2018.

MONTEIRO, M. A. A ICOMI no Amapá: meio século de exploração mineral. Novos Cadernos NAEA, v. 6, n. 2, 2003.

MOURA, R. et al. An extensive reef system at the Amazon river mouth. Science Advences, v. 2, n. 4, p. 1-11, 2016.

PINTO, L. F. Lúcio Flávio Pinto: A Agenda Amazônica de um Jornalismo de Combate. Disponível em: https://lucioflaviopinto.wordpress.com/. Acesso em: 09 mar. 2020.

PRETTY, J. et al. The Intersection of Biological and Cultural Diversity: Towards Integration. Conservation and Society, v. 7, n. 2, p. 100-112, 2009.

RALF, C. et al. C. Mesophotic coral ecosystems occur offshore and north of the Amazon River. Bulletin of Marine Science, v. 91, n. 4, p. 491-510, 2015.

RANGEL, K. S. Modo de vida e território na Reserva Extrativista do Rio Cajari (Amapá). 2017. Tese (Doutorado em Geografia Humana) - Faculdade de Filosofia, Letras e Ciências Humanas, Universidade de São Paulo, São Paulo, 2017.

ROMÃO, J. E.; GADOTTTI, M. Paulo Freire e Amílcar Cabral: a descolonização das mentes. São Paulo: Editora e livraria Instituto Paulo Freire, 2012.

SANTILLI, J. Socioambientalismo e Novos Direitos: Proteção Jurídica à Diversidade Biológica e Cultural. São Paulo: Fundação Peirópolis, 2005.

SANTOS, B. S. Para uma sociologia das ausências e uma sociologia das emergências. Revista Crítica de Ciências Sociais, 63, p. 237-280, 2002.

SANTOS, B. S. (org.). Semear Outras Soluções: os caminhos da biodiversidade e dos conhecimentos rivais. Rio de Janeiro: Ed. Civilização Brasileira, 2005.

SANTOS, B. S. A Gramática do Tempo. São Paulo: Cortez, 2006.

SANTOS, B. S. O Fim do Império Cognitivo: a afirmação das epistemologias do Sul. Belo Horizonte: Autêntica Editora, 2019.

SANTOS, B. S.; MENESES, M. P.; NUNES, J. A. Para ampliar o cânone da ciência: a diversidade epistemológica do mundo. In: SANTOS, B. S. (org.). Semear Outras Soluções: os caminhos da biodiversidade e dos conhecimentos rivais. Rio de Janeiro: Civilização Brasileira, 2005.

SANTOS, B. S.; MENESES, M. P. (Orgs.) Epistemologias do Sul. São Paulo: Editora Cortez, 2010.

SANTOS, V. F.; MENDES, A. C.; SILVEIRA, O. F. M. (coords.) Atlas de sensibilidade ambiental ao óleo da Bacia Marítima da Foz do Amazonas. Macapá: IEPA, 2016.

SAUTCHUK, C. E. O arpão e o anzol: técnica e pessoa no estuário do Amazonas (Vila do Sucuriju, Amapá). 2007. 401f. Tese (Doutorado em Antropologia) - Instituto de Ciências Sociais, Universidade de Brasília, Brasília, 2007.

SILVA, A. T. R. A conservação da biodiversidade entre os saberes da tradição e a ciência. Estudos Avançados, v. 29, n. 83, p. 233-259, 2015.

SILVA, F. J. R. O Conceito de Desenvolvimento no Pensamento de Arturo Escobar. Revista Pegada, v. 17, n. 2, p. 170-181, 2016.

SOARES, C. L.; CHAGAS, M. A. A. Vila Brasil e o Big Park: Perfil, Cenários e Paradigmas. In: SEMINÁRIO BRASILEIRO SOBRE ÁREAS PROTEGIDAS E INCLUSÃO SOCIAL, 4, no 1, Belém, 2009. Anais [...] Rio de Janeiro: Rodrigo Medeiros; Hilton Pereira da Silva; Marta de Azevedo Irving, 2009. p. 185-187. 
SOUZA, M. História da Amazônia: do período pré-colombiano aos desafios do século XXI. Rio de Janeiro: Record, 2019.

SVAMPA, M. Consenso de los commodities, giro ecoterritorial y pensamento crítico em América Latina. Revista del Observatorio Social de América Latina, ano XIII, n. 32, p. 15-38, 2012.

WILSON, E. (org.). Biodiversity. Washington, D.C.: National Academy Press, 1988. Disponível em: https://www.nap.edu/catalog/989/biodiversity. Acesso em: 12 jan. 2020.

WILSON, E. (org.). Biodiversidade. Tradução de Marcos Santos e Ricardo Silveira. São Paulo: Editora Nova Fronteira, 1997.

WILSON, E. A unidade do conhecimento: consiliência. Tradução de Ivo Korytowski. Rio de Janeiro: Campus, 1999.

WILSON, E. A Criação - como salvar a vida na terra. Tradução de Isa Mara Lando. São Paulo: Companhia das Letras, 2008.

WILSON, E. Diversidade da Vida. Tradução de Carlos Afonso Malferrari. São Paulo: Companhia das Letras, 2012.

WILSON, E. A Conquista Social da Terra. Tradução de Ivo Korytowski. São Paulo: Companhia das Letras, 2013.

WILSON, E. O Sentido da Existência Humana. Tradução de Érico Assis. São Paulo: Companhia das Letras, 2018.

WILSON, E. Da Terra Metade: A Luta do Nosso Planeta pela Vida. Tradução de Carla Morais Pires. Porto: Arte e Ciência, 2019. 